\title{
Madrid hacia 1920: Primeras hojas, de Alonso Zamora Vicente
}

\author{
Elena Cianca Aguilar ${ }^{1}$
}

Recibido: 6 de marzo de 2017 / Aceptado: 4 de octubre de 2017

Resumen. Madrid, en Primeras hojas, de Zamora Vicente, es un personaje que puede competir con los más importantes de carne y hueso que aparecen en el libro. Se recorre el libro de manera transversal en busca de los elementos que caracterizan aquella ciudad, los que componen su imagen: el tranvía, las verbenas callejeras, las cabalgatas, las procesiones, la plaza de Oriente, las Vistillas, el Casino, Rosales, los cines, la Casa de Campo... la calle en sus múltiples manifestaciones, pues la mayoría -no todos- son elementos exteriores. En su afán por convertir a Madrid en un personaje, Zamora Vicente da relieve a elementos tan intangibles como la luz o el sonido, que tanta atmósfera proporcionan al libro. A pesar de recoger muchos elementos del Madrid real de 1920, Primeras hojas no es un documento histórico. Todo lo que aparece en él está pasado por el tamiz del lenguaje y de los procedimientos literarios.

Palabras clave: Alonso Zamora Vicente; Primeras hojas; Madrid.

\section{[fr] Madrid vers 1920: Premières feuilles, par Alonso Zamora Vicente}

Résumé. Madrid, dans Primeras hojas (Premières feuilles), de Zamora Vicente, est un personnage digne de rivaliser en importance avec les plus grands de chair et d'os présents dans le livre. On parcourt ce livre de manière transversale à la recherche des éléments qui caractérisent cette ville, ceux qui conforment son image: le tramway, les bals populaires, les défilés des Rois Mages, les processions, la place d'Orient, les Vistillas, le Casino, Rosales, les cinémas, la Casa de Campo... la rue sous ses multiples manifestations, car pour la plupart -non pas tous- ce sont des éléments extérieurs. Dans son souci de transformer Madrid en un personnage, Zamora Vicente met en relief des éléments aussi impalpables que la lumière ou le son qui procurent tant d'atmosphère à ce livre. Bien qu'ayant repris beaucoup d'éléments du Madrid réel de 1920, Primeras hojas n'est pas un document historique. Tout ce que l'on y retrouve est passé au crible du langage et des procédés littéraires.

Mots clés: Alonso Zamora Vicente; Premières feuilles; Madrid.

Sumario: 1. La ciudad como personaje; 2. Recuerdos de niñez de Zamora Vicente; 2.1. El Madrid exterior; 2.2. El Madrid interior; 2.3. Madrid: paisaje urbano y rural; 3. Dramatis personae; 4. Lugares de ocio; 5. Madrid: luz y bullicio; 6. A modo de conlusión; 7. Referencias bibliográficas.

Cómo citar: Cianca Aguilar, E. (2017). Madrid hacia 1920: Primeras hojas, de Alonso Zamora Vicente, en Revista de Filología Románica 34. Núm. especial, 81-88. 


\section{La ciudad como personaje}

Madrid no es un mero escenario en Primeras hojas ${ }^{2}$. La ciudad se integra en el libro como un personaje necesario, de constante presencia, hilo conductor de todos los acontecimientos que se narran. Es fácil reconocer actualmente el Madrid de Primeras hojas, especialmente en lo urbanístico. Contribuye a ello la permanencia del núcleo antiguo de Madrid, de sus calles (Alcalá, Don Pedro, Rosales, Cibeles...), de sus edificios (la catedral de San Isidro, las iglesias, el casino), de sus espacios, jardines y parques, como Las Vistillas, la Casa de Campo. Van a cambiar o a desaparecer, sin embargo, los negocios, las tiendas de alfarería, de esparto, la churrería. También las personas, la señora que vendía los periódicos, el cura, el médico, la portera, los vecinos. Digamos que Madrid nos sigue ofreciendo la estructura inmutable de su casco viejo, mientras que Primeras hojas nos mostrará, de manera literaturizada, las vidas de las gentes de aquellos años, a través de la voz del niño protagonista o del adulto en el que se convirtió.

Habrá aspectos por los que el Madrid de hacia 1920, en Primeras hojas, presenta una fisonomía muy diferente a la actual. Se empiezan a ver circular por sus calles coches, que en el libro se denominarán autos o automóviles, como en aquellos años, para distinguirlos de los coches de caballos, por entonces todavía habituales entre la clase más acomodada, a diferencia de la mayoría de la población, que se desplazará en tranvía. El tranvía está muy presente en Primeras hojas. El tranvía que les lleva a Rosales, a los paseos vespertinos: "Tomamos el tranvía en la puerta de Capitanía General" (1985:63-64). El tranvía de la Bombilla, adonde van unos recién casados y sus invitados a celebrar su boda (realmente eran otros tiempos): "De un tranvía con jardinera salen gritos y cantos, será una boda que va a la Bombilla" (1985:114-115). El tranvía que les acerca a la estación de Goya, para tomar el tren que les va a llevar a la casita que tenían en Campamento: "El tranvía bajaba despacito la pendiente de la calle Toledo" (1985: 41-42).

\section{Recuerdos de niñez de Zamora Vicente}

La infancia que se narra en Primeras hojas es la infancia de Zamora Vicente filtrada por el tamiz del recuerdo. Como el punto de vista sobre el que gira toda la narración es el del niño, que en general también es el narrador, conoceremos exclusivamente lo que él observa, lo que oye, lo que siente, lo que vive. No estamos ante un narrador omnisciente que nos sirve de guía.

Todo lo que acontece en estas páginas tiene una base autobiográfica, pero sobre esta base se aplica un tratamiento literario que debe distanciarnos de considerar la obra como un documento histórico o social estrictamente.

\subsection{EI Madrid exterior}

Madrid es un espacio muy querido por su autor. En este sentido, nos parece relevante destacar que su primera obra literaria es un libro esencialmente de exteriores.

2 Las citas que aparecen en este artículo corresponden a la segunda edición de Primeras hojas (Madrid, Espasa-Calpe, 1985), que cuenta con cuatro relatos más que la primera, publicada en la editorial Ínsula, en 1955. 
En él se narran las salidas, los paseos, el entretenimiento del niño. ¡Cuántas veces se mencionan, sin embargo, los sitios adonde no podrá acudir por su condición de niño! En el capítulo "La cabalgata", después de disfrutar de los preparativos para acudir a ella, el niño se da cuenta de que no va a asistir, de que la cabalgata tiene lugar por la noche y él no va a ningún espectáculo de noche: "Por donde irán las carrozas, y si llevarán luz, y nunca me dijisteis que la cabalgata era de noche..., ya sé que yo, de noche, claro, con tantas apreturas..." (1985:181-182).

En el capítulo "La verbena" se nos cuenta cómo era la verbena de la Paloma, en pleno agosto. Llegaban las fieras de los espectáculos; se montaban los caballitos, los columpios, la noria, etc., pero no asistiremos, como el niño, a la verbena por la noche, solo veremos lo que contempla desde el balcón de su casa: "Por la noche la kermés era en el atrio de la iglesia de San Andrés y un par de plazuelas más, muy bien aisladas con vallas de madera, y yo la veía desde los balcones, solo y cabeceando" (1985:128). En numerosas ocasiones se le prohíbe, o se le aparta, de lo que no debe escuchar. La calle es un mundo de adultos. En el capítulo "Música en la calle", el francés, con su bombo y sus platillos, se paraba en la panadería de la calle a cantar: "A menudo cantaba cosas que yo no entendía, y entonces me quitaban deprisa del balcón" (1985:60).

Los lugares por donde pasea el niño están relacionados con el esparcimiento, con el recreo de un niño de clase media, adonde acude con su familia, cuando estos disfrutan, a su vez, de su tiempo libre. Suele ser los domingos u otros días festivos. El niño siempre pasea, no juega con otros niños, no va al parque. Todavía es pequeño, tiene seis o siete años. También visitan frecuentemente la plaza de Oriente, tan cercana a la casa de los personajes, donde los niños podían subirse al cochecito que daba la vuelta al óvalo de la plaza, o comprarse un barquillo, o escuchar las historias del hombre del cartelón. La plaza se repite frecuentemente a lo largo del libro. Pero cobra protagonismo en el episodio "Escapada". Allí acude el niño en su huida de casa, después de recorrer los espacios habituales de juego, como los terraplenes de Las Vistillas, por donde se deslizaba sobre cartones.

Las Vistillas y las calles cercanas a su vivienda eran espacios por donde paseaba frecuentemente con su padre muchos domingos. Comienza la narración de "Mañana de domingo" diciendo: "mi padre me llevaba a todas partes" (1985:35). El cine, al que iba con sus hermanos, era uno de los entretenimientos más habituales, especialmente durante el invierno. Zamora va a dedicar un capítulo a esas tardes de cine. Comienza la historia con los gritos de los vendedores ofreciendo golosinas y revistas, Blanco y Negro, Nuevo Mundo, Mundo Gráfico, Muchas gracias. Nos describe estas tardes de cine, que tanto le gustan al niño, nos mete en su atmósfera, en sus ajetreos, en sus risas. Poco importa el nombre del cine. No nos lo dirá. Y no deja de resultar extraño que no lo haga, ya que Zamora tiende a acompañar todo con su nombre. Dará los nombres de los comercios (Almacenes Perpiñán, Almacenes El Águila, El Sol, La Eficaz, etc.), de los toreros (El Niño de la Palma, Belmonte, etc.), de las personas conocidas de la vida social o política, cuando la familia pasa por delante de sus casas, como la del general Weyler, o la de infanta Isabel de Borbón, en el entorno del paseo de Rosales. Pero se ve que lo que realmente le importa destacar de estas tardes son los momentos vividos. Otro de los lugares de paseo será la Casa de Campo. Únicamente podían acceder quienes contaban con permiso, un privilegio. Era propiedad de la Casa Real. En algunas de estas visitas se podía coincidir con el rey o con las infantas. Si los veían, daba lugar a tarde de comentarios: su forma de vestir, sus movimientos, etc. 


\subsection{El Madrid interior}

Los escenarios de Primeras hojas, como ya se ha dicho, son escenarios exteriores. Pertenecen principalmente a la ciudad, a un ambiente urbano, en muchas ocasiones restringido al barrio del protagonista. Nos encontraremos, no obstante, con varios episodios que se desarrollan en interiores. En "Aleluyas" el escenario será la casa familiar, es decir, un interior. Pero la actividad que están realizando se proyecta hacia fuera. Aquí los chicos recortan las aleluyas -hojas con estampas que narran una historia- y las van echando a la calle, como si fuera confeti, al paso de la procesión. El entretenimiento, por tanto, lo encuentran en el exterior, en la calle.

También "De visita" tiene lugar en un interior. Sin embargo, cuenta algo que pasa fuera de la casa; es una salida, una actividad más de la que participan frecuentemente los personajes. En este caso se narra una de las ocupaciones habituales de aquellos años en el tiempo libre: la de visitar a la familia o a las amistades. A una de las visitas que hacían a la tía Plácida está dedicado este capítulo. Plácida vivía en una casa "señorial" cercana al "museo" -al museo del Prado-. El tiempo libre al que nos hemos referido se expresa explícitamente en el relato. Corresponde a los jueves por la tarde, cuando los niños no tenían colegio, o a la tarde del sábado, porque al día siguiente no había que madrugar.

El único episodio ambientado en el interior -en la casa familiar-, en el que no se desarrolla una actividad hacia fuera, será "Alucinación", donde se nos habla de las tardes de invierno en las que se aparecía Camuñas o el Coco para asustar a los niños. (Dejamos a un lado "Viejos retratos", que no corresponde propiamente al presente narrativo del resto del libro, al igual que "Revés de la tarde, último capítulo", broche de la segunda edición).

\subsection{Madrid: paisaje urbano y rural}

Tampoco el Madrid de Primeras hojas será un escenario cerrado, sino que la ciudad se proyectará hacia fuera. Es un Madrid abierto, sin límites. La mirada se pierde en el horizonte. Un Madrid que se aleja muchos kilómetros. Hay un momento en que el narrador se coloca primeramente en el centro del viaducto -se trata de un anterior viaducto, de hierro-, que salva la hondonada de la calle de Segovia, entre los cerros de Las Vistillas y de la Armería. A un lado, mirando hacia la ciudad, va fijándose en cada una de las iglesias: Las Bernardas, la iglesia de San Miguel, la de Santa Cruz, etc.

Continúa la descripción girando la mirada hacia el exterior de la ciudad. No lo dirá, pero tendrá que cruzar la calzada, por donde circularán coches de caballos y autos, para poder divisar con claridad La Florida y los montes que nos nombra. Hoy no los podemos ver desde el lugar donde se ubica el narrador. El seguro que sí, porque no tenía a su derecha las construcciones que los tapan: un edificio de viviendas, las dependencias del Ayuntamiento, la catedral de la Almudena, que estaba levantándose, aunque no se dice abiertamente, sino aludiendo al sonido de la grúa, como se ve en la siguiente cita:

Pude meter algo de comer, pero, claro, salí tan deprisa, se creían que no me iba a ir, pues ya lo ven, y más saltos y carreras, y ahora están regando la calle, gracioso ver el tranvía reflejado en el asfalto, el arco iris bajo el chorro, el quejido largo de una grúa en la Almu- 


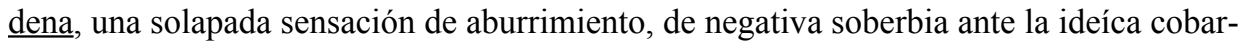
de (¿quién me está hablando?) de volver a casa, y disgusto por esta bolsa sin pan, ya me está cansando $(1985: 115)^{3}$.

Y de manera sugerida, igualmente en su obra Examen de ingreso:

Puntuales, con la Virgen de setiembre (sic), llegaban las tormentas. Un inmenso incendio, destellando sobre los nubarrones oscuros, se acercaba desde la Casa de Campo, grandes goterones, oscuridad súbita desplomándose sobre el Parque del Oeste, el Palacio, $\underline{\text { los }}$ muñones de la Almudena creciente, y el ventarrón se llevaba los toldos, todo el mundo corría tras ellos, algunos llegaban hasta la entrada del Viaducto, donde las mesas de un aguaducho rodaban por las aceras (1991:34).

No hablará de unas vistas bonitas, como valoramos hoy esa panorámica -Las Vistillas, quizá de ahí su nombre-, sino que se detiene en dar los nombres de los picos que desde allí se divisan. En un primer momento podría parecer que estos topónimos no los conocía el niño, sino que forman parte de los conocimientos del adulto que está recordando:

También campo abierto, Casa de Campo adelante, y La Florida, humo de trenes, y nombres de montañas, lejos: Montón de Trigo, La Maliciosa, Peñalara, Siete Picos, Abantos. “Allí está El Escorial”, decía mi padre, señalando. Y yo nunca veía El Escorial, sino casas, lomas, alguna nube, y horizontes, perennes luego, que no se parecían al Escorial, el edificio de muchas torres y pizarra oscura que yo encontraba en los libros, o en un manguillero de hueso con un agujerito de cristal que alguien me había traído de allá, no logro recordar cómo ni cuándo (1991:36 y 39).

Sin embargo, en Examen de ingreso le encontraremos aprendiendo con los hermanos cada uno de estos nombres.

El Madrid urbano acaba a pocos metros de la casa del protagonista. Las inmediaciones del río Manzanares, de camino a la estación de Goya, donde cogerán el tren que les acercará a la casita de campo, está lleno de huertas. De "huertas pobretonas", nos dice el narrador (1991:83). El libro se desarrolla también en los alrededores de la gran urbe. En Campamento (hoy un barrio de Madrid), donde se ubicaba precisamente esta casa de campo: "Vamos a pasar el día, o varios días, al campo, en el huerto de papá" (1985:83). Uno de los capítulos se ambientará fuera de la ciudad, en un pueblo de la Comunidad de Madrid: Arganda del Rey. La vinculación con el protagonista se debe a que en él vive la hermana mayor de su madre. Allí irá a pasar unos días tras su muerte. Hay un único escenario ajeno a Madrid. Se trata del pueblo de la familia, cerca de La Roda, en Albacete, adonde los chicos van a pasar el verano con sus tíos y con sus primos.

El subrayado de las citas que se incluyen en este artículo no pertenece a la obra original, sino que responde al propósito de enfatizar los fragmentos que se analizan. 


\section{Dramatis personae}

Además del paisaje urbano, en Primeras hojas también se refleja la sociedad madrileña del momento. Es un Madrid lleno de contrastes, en el que, al igual que conviven lo rural (las huertas del Manzanares) y lo más urbano (los tranvías, los autos, los cines, el casino o los espectáculos de cuplés), también lo harán vendedores y músicos callejeros, toreros, etc., con la burguesía, con los notarios, con los médicos. Es un Madrid, el de entonces, que, como dice el mismo Zamora en Examen de ingreso, "ansiaba abandonar su cáscara pueblerina para convertirse en gran ciudad" (1991:30).

Tenemos la sensación de que estas páginas están muy pobladas de personajes, especialmente de personajes populares. Sin embargo, no van a mostrarse muy detallados, sino, al contrario, están presentados de un solo trazo. El violinista callejero quedará descrito escuetamente como ciego, viejo, de barbas blancas y sucio. No habrá descripción del hombre del organillo. Lo mismo ocurre con el francés. Nada sabremos de su aspecto. Solo le identificarán los instrumentos que va tocando por las calles. De Dorotea, se dirá simplemente que era "una criada mayorcita" (1985:47). Ni una palabra explícita sobre el físico de la tía Plácida. La conoceremos por las cosas que la rodean, atesoradas a lo largo de su vida (1985:107). En el capítulo "Colegio" no se describe al maestro o a los compañeros. Solo se indica que uno de ellos es bizco, y que le causa el desasosiego de no saber si le está mirando. No habrá descripciones, ni siquiera de los miembros de la familia. Si acaso, cuando contemplan el álbum familiar, en el primer capítulo, "Viejos retratos", se nos da algún detalle más, especialmente del atuendo. Pero, igualmente sin exhaustividad, para caracterizar brevemente al retratado, casi siempre un pariente lejano:

Allí están los abuelos, seriecitos, sombrero hongo y cuello alto él, la falda interminable ella, el abanico semiabierto, colgado al cuello con una delgada cadenita de oro, y la deslumbrante pulsera, regalo de pedida, se la trajeron de París. Los adornos del polisón apenas se adivinan bajo el amarillo terroso de la lámina (1985:29).

Estos ejemplos nos llevan a pensar que Primeras hojas es un libro de hechos. Los personajes formarán parte activa de las historias, incluso serán autores de muchas de las acciones que se narran, pero casi de manera anónima, porque lo importante para el niño es lo que hacen. No se va a parar a describir cómo eran. Falsearía el relato. No olvidemos que la voz narradora, principalmente, es la de un niño. Tampoco olvidemos que todo lo que se describe en Primeras hojas es un recuerdo. Y en los recuerdos perviven especialmente las características más significativas. Quizás por eso utilice el mismo procedimiento, de trazo rápido, también al tratar el paisaje. Por ejemplo, al hablar del campo de Arganda: "[la tía Rosa] Vivía en Arganda del Rey, cerca de Madrid, entregados ella y su marido, Gregorio, a cuidar sus olivos, sus vinos, sus fábricas de esto y de lo otro" (1985:76). Y más adelante:

Algunas tardes me llevaba de paseo al cerro de la Horca, cuesta empinada de guijarros, unos pinos en lo alto, campo sosegado a lo lejos, el pueblo entero abajo. Desde allí me explicaba chismes del lugar, de quién era aquella viña, de quién aquel maíz o la noria del otro bancal (1985:76). 
Llegan las influencias de París. La modernidad de lo extranjero choca con una mentalidad conservadora y tradicional. En "Tarde en Rosales" la hermana mayor, Elisa, quiere alquilar unos patines, disfrutar como las patinadoras, unas jóvenes elegantemente vestidas, de la clase alta. Pero el novio se lo impedirá. Querrá que se muestre recatadamente: "Elisa quería alquilar unos patines, pero el novio no la dejaba, eso son cosas de ahora, un escándalo, esas son francesas que traen de reclamo, una señorita no debe hacer eso, y luego, si te caes y echas las piernas por alto" (1985:65).

\section{Lugares de ocio}

Ese Madrid de contrastes se abría camino como ciudad moderna, en la línea de otras capitales europeas. En este mismo capítulo se nombra Parisiana. Se trata del espacio más lujoso de la alta sociedad madrileña de principios del siglo XX, con restaurante, salón de té, espectáculos, casino. Se inauguró en 1907 y desapareció en la Guerra Civil, al estar dentro del frente de batalla de la Ciudad Universitaria, en Moncloa. Otro de los lugares de diversión de más prestancia al que acudía la sociedad madrileña de los años veinte era el casino. En estos años el casino de Madrid ya se encontraba ubicado en el número 15 del actual edificio de la calle Alcalá. Se inauguró el 29 de septiembre de 1910, según reza una placa en su fachada. En el primer capítulo, "Viejos retratos", se hace mención al baile de carnaval al que asistió, allí, la familia del protagonista.

La mayor parte de las actividades de la sociedad madrileña de los años veinte que se reflejan en Primeras hojas son colectivas y se desarrollan en la calle, el espacio de todos: las procesiones, las verbenas, las cabalgatas, etc. La calle es el principal escenario. Por esta razón las preocupaciones por la meteorología y las referencias a las estaciones del año se repiten. Incluso parece que hay una ordenación estacional de los textos.

Nos despertábamos temprano, temerosos de que hiciese mal tiempo. No se esperaba en la cama, duermevela contenta, como otras mañanas, a escuchar el ruido creciente de la calle, el trepidar de los camiones en el empedrado, el taladro de un pregón. Todos esos ruidos que revelan el sol, la mañana clara y decidida, con su perfume aún amontonado. No, no se esperaba en la cama. Nos levantábamos todos a mirar el cielo por los balcones, por las ventanas del patio, por la escalera, si se nublará, si estará la tarde bien, y a preguntar a todos los que podíamos hará una tarde estupenda? lejano temor de que contestaran otra cosa, no un a lo mejor llueve, o hará frío, sino no sé, o déjame en paz, tengo que hacer ahora, sino algo que fuese afirmación de sol y dicha inaplazables. Felicidad del Jueves Santo, un compacto silencio de fiesta en la calle, los tranvías como siempre renqueando (1985:161-162).

En este sentido, el sol es también un elemento destacado de Primeras hojas. Será siempre un sol agradable, que les permite disfrutar de los paseos, de las procesiones, de las cabalgatas, salir a pasear en los días más fríos a la hora en que el sol calienta más. Hay muchos pasajes que muestran la importancia del sol en el libro.

Algunos jueves por la tarde no hay colegio, vamos después de comer a tomar el sol a la explanada de Palacio. Sol tibio y ya bajo de las cuatro, claridad inverniza, una frágil niebla atesorando humos sobre el río (1985:153).

Regreso despacito, sol bueno del mediodía, esta tarde podré dejar sin miedo el abrigo, abrigo empieza por A, creí que lo perderían, dos dedos en alto para ir a los lugares (1985:150). 
Iremos a la cabalgata, saltos por el comedor, por el pasillo, carreras desde el mirador a la cocina, un sol tibio y amable rompiéndose en los cristales y sobre la alfombra, y en el brazo lustroso de una butaca, y sobre la orilla blanca de un cenicero, y en las fallebas del balcón, y en el almanaque de Vicente Rico, papelería y objetos de escritorio, el almanaque con carpeta donde se guardan los recibos del agua y de !a luz, y del sereno, y de los pobres de la parroquia, y del médico, y de la Purísima Concepción, mutualidad para entierros... Sol. Hace sol, cosa tan buena cuando se espera fiesta por la tarde (1985:179-180).

\section{Madrid: luz ybullicio}

El Madrid que refleja Alonso Zamora Vicente en Primeras hojas es, pues, un Madrid muy luminoso, lleno de sol. Y el sol, como dice el narrador es dicha, es fiesta en la calle.

Es también un Madrid bullicioso: el traqueteo de los tranvías, el silbido de los trenes, el tintineo del carro de la basura, los cláxones, la música callejera, las voces (o pregones, como se dice insistentemente en el libro) de los vendedores ambulantes, las verbenas, las procesiones, el griterío de la gente, el repicar de las campanas de las iglesias... Sonidos de la calle que se meten en el interior de las casas y se integran en la cotidianidad diaria:

No se esperaba en la cama, duermevela contenta, como otras mañanas, a escuchar el ruido creciente de la calle, el trepidar de los camiones en el empedrado, el taladro de un pregón. Todos esos ruidos que revelan el sol, la mañana clara y decidida, con su perfume aún amontonado. (1985:161).

El chirriar del tranvía que se entra poderoso por la casa (1985:100).

\section{A modo de conclusión}

Los sonidos del Madrid de 1920 forman, sin ninguna duda, la banda sonora de Primeras hojas. Incluso la manera de hablar de aquellas gentes, que resuena en la memoria del escritor, y que nos la ofrece, casi podríamos decir, como un documento sonoro de aquellos años veinte: “¡Aleluyas, aleluyas de toos los colores!" (1985:73). El Madrid de Primeras hojas sale del recuerdo de Alonso Zamora Vicente. Es el Madrid del protagonista, un niño de siete años, que siempre va con su familia, que nos enseña su entorno más inmediato, el del casco viejo. Es un Madrid castizo, principalmente urbano, lleno de gentes, de muy diferente condición social, que pueblan sus calles. Es un Madrid entre pueblerino y cosmopolita. Luminoso y sonoro. Desde luego es un elemento fundamental de Primeras hojas, es el escenario de un mundo feliz. Creo que Zamora Vicente escribió Primeras hojas principalmente con la intención de rescatar para sí mismo ese período feliz de su infancia, como señas de su identidad verdadera.

\section{Referencias bibliográficas}

Zamora Vicente, Alonso (1985): Primeras hojas [2.' ed., que añade cuatro textos]. Madrid: Espasa-Calpe.

Zamora Vicente, Alonso (1991): Examen de ingreso. Madrid, años veinte. Madrid: Espasa-Calpe. 